\title{
Antimicrobial resistance in pathogens causing nosocomial infections in surgery and intensive care wards in Antananarivo, Madagascar
}

\author{
Frédérique Randrianirina ${ }^{1}$, Laetitia Vaillant ${ }^{1}$, Charles Emile Ramarokoto ${ }^{1}$, Armand \\ Rakotoarijaona ${ }^{2}$, Mamy Lalatiana Andriamanarivo ${ }^{2}$, Henri Claude Razafimahandry², Jules \\ Randrianomenjanahary ${ }^{3}$, Jean Roger Raveloson ${ }^{3}$, Elisoa Ratsima Hariniaina ${ }^{1}$, Jean-François \\ Carod $^{1}$, Antoine Talarmin ${ }^{1}$, Vincent Richard ${ }^{1}$ \\ ${ }^{1}$ Institut Pasteur of Madagascar - BP1274 - 101 Antananarivo - Madagascar \\ ${ }^{2}$ Hôpital Joseph Ravoahangy Andrianavalona - 101 Antananarivo - Madagascar \\ ${ }^{3}$ Centre Hospitalier Soavinandriana - 101 Antananarivo - Madagascar
}

\begin{abstract}
Background: In developing countries, knowledge of antimicrobial resistance patterns is essential to define empirical therapy.

Methodology: All the surgery and intensive care wards of two hospitals in Antananarivo were included to study the antimicrobial susceptibility of the pathogenic bacteria causing nosocomial infections. A repeated cross-sectional survey was conducted between September 2006 and March 2008, one day per week. Isolates were identified using classical methods, and resistance to antibiotics was assessed according to the recommendations of the Antibiogram Committee of the French Microbiology Society.

Results: Clinical specimens from 706 from 651 patients were collected. Of the 533 bacterial pathogens, 46.7\% were Enterobacteriaceae, $19.3 \%$ were Staphylococcus aureus, and $19.1 \%$ were pathogens from the hospital environment (Pseudomonas aeruginosa and Acinetobacter baumannii).Frequencies of resistance were high, particularly in Enterobacteriaceae; however, the rate of Staphylococcus aureus isolates resistant to oxacillin $(13.6 \%)$ was moderate and all these isolates were susceptible to glycopeptids. The percentages of isolates susceptible to ceftazidim were $81.8 \%$ for E. coli, $60.9 \%$ for Klebsiella, and $52.5 \%$ for Enterobacter spp. Resistance to third-generation cephalosporins was due to extended spectrum betalactamases (ESBL). Multivariate analysis showed that diabetes (adjusted OR: 3.9) and use of an invasive procedures (adjusted OR: 3.5) were independent risk factors for resistance to third-generation cephalosporins.

Conclusion: A nationwide surveillance programme is needed to monitor the microbial trends and antimicrobial resistance in Madagascar.
\end{abstract}

Key words: nosocomial infection, bacterial resistance, Madagascar, surgery wards, intensive care wards

J Infect Dev Ctries 2010; 4(2):074-082.

(Received 28 August 2009 -- Accepted 10 November 2009)

Copyright (C) 2010 Randrianirina et al. This is an open-access article distributed under the Creative Commons Attribution License, which permits unrestricted use, distribution, and reproduction in any medium, provided the original work is properly cited.

\section{Introduction}

Hospital-acquired infections result in significant morbidity and mortality, and contribute to escalating health care costs [1].The emergence of resistance to antimicrobial agents, despite the availability of newer antibiotics, has become an increasing problem throughout the world, particularly in pathogens causing nosocomial infections [2-4]. For practising physicians, clinical microbiologists and public health officials, knowledge of local antimicrobial resistance patterns is essential for the development of empirical and pathogen-specific therapy. The distribution of pathogens causing nosocomial infections changes with time and varies among hospitals. Information about antimicrobial resistant pathogens is critical for effective decisions to be made on infection control policies, the rational formulation of public health care policies, and the national and international research agendas in this area. Unfortunately, data on endemic antimicrobial resistance are unavailable from many parts of the world, especially from areas where overthe-counter antibiotic use is common.

Few studies have been conducted examining endemic antimicrobial resistance in Madagascar $[5,6]$. However, observations at the Pasteur Institute of Madagascar, of antimicrobial resistance of bacterial isolated from hospitalized patients, have suggested that it could be a public health problem. This study aimed to identify antimicrobial resistance patterns among bacterial isolates causing nosocomial infection in twelve departments of two hospitals in Antananarivo, the capital city of Madagascar.

\section{Materials and methods}

Setting 
The study was performed at the hospital Joseph Ravoahangy Andrianavalona (HJRA) and the Soavinandriana hospital (CENHOSOA), Antananarivo, Madagascar. With more than 700 beds, HJRA is the largest hospital in the country and serves as a national university teaching hospital. The CENHOSOA is the country's military hospital, with more than 470 beds. These two hospitals are referral hospitals for a population of approximately 1.5 million in the Antananarivo area.

To target the units most at risk of nosocomial infections, we included a total of 12 wards from the two hospitals: intensive care $(\mathrm{n}=2)$, visceral surgery $(\mathrm{n}=5)$ and trauma units $(\mathrm{n}=5)$.

The Pasteur Institute of Madagascar examines specimens from inpatients and outpatients from a number of hospitals in Antananarivo. Bacteriological cultures are performed on more than 8,500 specimens each year.

\section{Sample methods}

For logistical and financial reasons, the study was a repeated cross-sectional survey with systematic sampling. All inpatients presenting a nosocomial infection on a given day each week between September 2006 and March 2008 and in each participating department were recruited to the study. To eliminate duplicates, only one sample was taken per patient and per site.

Nosocomial infection was defined as any infection that occurred more than 48 hours after admission of the patient to hospital. Any patient who had an infection on admission and had not recovered from that episode the day of the survey and any inpatient who had been hospitalized for fewer than three days was not considered a nosocomial infection case. All other inpatients who, on the day of the survey, had signs of infection or were identified as infection cases by the ward doctor were considered to suffering from a nosocomial infection. Only active infections (i.e. symptomatic or considered ongoing and needing antimicrobial treatment by medical staff) were included.

Data were collected from questionnaires filled out by two senior medical epidemiologists training in hospital infection studies from the Institut Pasteur of Madagascar, who used case notes and the ward doctor as sources of information. For each patient included, the following information was recorded: age, sex, date of admission, ward, admitting diagnosis, site and symptoms of infection on admission, recovery from admitting infection, underlying disease, history of past hospitalization, history of invasive devices used, history of antibiotic treatment before admission, treatment during hospitalization (antibiotic therapy, invasive devices used), site and symptoms of infection on day of survey, date of clinical sampling, and site of surgery if any. Clinical specimens were collected before antimicrobial treatment for microbiology analysis and the study investigation form was completed with the results of the laboratory diagnosis and data of antimicrobial susceptibility.

\section{Laboratory methods}

The specimens, from deep pus, surgical wounds or urinary tract infection (UTI), were cultured at $37^{\circ} \mathrm{C}$ overnight. Blood samples were collected using a conventional blood culture bottle (Hemoline performance diphasique; BioMérieux), cultured at $37^{\circ} \mathrm{C}$ and were observed twice a day for seven days.

Bacterial isolates were identified using standard microbiological methods, as previously described [6,7]. The susceptibility of bacterial isolates to antibiotics was tested using the disc diffusion method, as described by the Antibiogram Committee of the French Microbiology Society [8]. Antibiotic discs were obtained from Biorad, Marne la Coquette, France.

The antibiotics tested were recommended by the CASFM. The zone of inhibition was measured after 24 hours at $37^{\circ} \mathrm{C}$. To detect extended spectrum betalactamases (ESBL), discs of ceftazidim and cefotaxim were placed $30 \mathrm{~mm}$ from an amoxicillinclavulanate $(20 / 10 \mu \mathrm{g})$ disc. An increased zone of inhibition between the clavulanate disc and any one of the third-generation cephalosporin discs indicated the presence of an ESBL. The distance between the discs could be reduced when the synergy was not easily observed as in cephalosporinase-producing strains. Cefoxitin discs were used to test for resistance to methicillin in Staphylococcus aureus.

S. aureus ATCC 25923, Escherichia coli ATCC 25922, and Pseudomonas aeruginosa ATCC 27853 were included as control strains. Criteria for susceptibility or resistance followed the CASFM guidelines [8]. The isolates showing intermediate resistance were grouped together with resistant isolates for the purpose of data analysis. The resistance rate was calculated as the number of nonsusceptible isolates divided by the total number of isolates.

\section{Statistical methods}


Data were analysed using Statistica Software, version 5.5 (Statsoft Corporation, OK, USA). Proportions for categorical variables were compared using $\chi^{2}$ tests, although Fisher's exact test was employed for small amounts of data. $\mathrm{P}<0.05$ was considered significant, using two-sided comparisons. A multivariate model was performed using backward stepwise analysis for multi-resistance concerning Enterobacteriaceae and S. aureus.

\section{Ethical clearance}

The study was approved by the Ministry of Health and the National Ethics Committee of Madagascar. For each confirmed infection case, treatment was instituted according to the laboratory results reported to each care ward.

\section{Results}

During the study period, 706 clinical specimens were collected from 651 inpatients, of whom 487 (74.8\%) were hospitalized in HJRA and 164 (25.2\%) in CENHOSOA. Only one specimen was collected for 601 patients $(92.3 \%)$, two for 45 patients $(6.9 \%)$ and three specimens for 5 patients $(0.8 \%)$. The sex ratio $(\mathrm{M} / \mathrm{F})$ was 1.25 (55.4\% male and $44.6 \%$ female). Clinical specimens were positive for at least one pathogen in $57.1 \%(\mathrm{n}=403)$ of cases. The majority of clinical specimens were obtained from surgical wounds $(64.0 \%, 452 / 706)$, deep layer pus $(19.1 \%, 135 / 706)$, and blood cultures $(9.1 \%, 64 / 706)$.

\section{Bacterial isolates}

A total of 533 bacterial pathogens causing nosocomial infections were recorded during the study period, of which $68.9 \%(\mathrm{n}=367)$ were Gramnegative and $31.1 \%(n=166)$ Gram-positive bacteria. The most frequently encountered bacterial pathogens were Enterobacteriaceae [46.7\%, $\mathrm{n}=249$ : (Escherichia coli, Klebsiella pneumoniae, Enterobacter cloacae, Morganella. morganii, Proteus mirabilis, Klebsiella oxytoca,Enterobacter. sakazakii)], Staphylococcus aureus $(19.3 \%, \mathrm{n}=103)$, and bacterial pathogens from the hospital environment (19.1\%, $\mathrm{n}=102$ :Pseudomonas aeruginosa and Acinetobacter baumannii).

Table 1 shows the bacteria most frequently isolated from the various specimen types, considered together or separately. The frequency of bacteria isolates differed between care units $(\mathrm{p}<0.01$; Table $2)$. E. coli were more frequent in visceral surgery units $(41.2 \%, \mathrm{n}=47), S$. aureus in trauma units $(25.7 \%, \mathrm{n}=92)$, and Klebsiella Spp. $(18.0 \%, \mathrm{n}=11)$ and Pseudomonas spp. $(16.4 \%, \mathrm{n}=10)$ in intensive care units.

\section{Antimicrobial susceptibility}

Tables 3 and 4 show the frequency of antimicrobial susceptibility of the most frequently isolated Gram-negative and Gram-positive bacteria, respectively. The susceptibility of different strains to antibiotics showed that the resistance rates of gramnegative bacilli (resistant plus intermediate) were $90.5 \%$ for amoxicillin (229/253), 58.7\% for cotrimoxazol (249/424), 26.7\% for ceftazidim (97/365) and $15.9 \%$ for imipenem $(28 / 176)$.

Enterobacteriaceae, especially $K$. pneumonia, displayed multiple resistance to many antimicrobials tested but were uniformly susceptible to imipenem $(100.0 \%)$. Of the 249 Enterobacteriaceae, 58 $(23.3 \%)$ were resistant to third-generation cephalosporins; ESBL production was confirmed in $53(91.4 \%)$, and five (8.6\%) overproduced Amp-C betalactamase.

$P$. aeruginosa showed a moderate rate of resistance against antipseudomonal penicillins (piperacillin $12.8 \%$, ticarcillin $31.9 \%$ ) and all strains were susceptible to ceftazidim. A. baumannii were much more resistant; $74.5 \%$ of strains were resistant to ticarcillin, $85.1 \%$ to chloramphenicol, $62 \%$ to ceftazidim and $44.7 \%$ to imipenem.

The rates of $S$. aureus resistant to oxacillin (MRSA) were moderate (13.6\%). All staphylococcal isolates were susceptible to vancomycin.

Enterobacteriaceae risk factors for resistance to third-generation cephalosporins

In univariate analysis (table 5), the risk factors for acquiring resistance to third-generation cephalosporins in Enterobacteriaceae were as follows: coming from care unit (OR: $1.9 ; 95 \% \mathrm{CI}$ : [1.1-3.7]), having diabetes (OR: 3.5; 95\% CI [1.39.6]), invasive procedures during hospitalization (OR: 3.1; 95\% CI [1.2-7.2]) and urinary catheterisation (OR: 2.2; 95\% CI [1.1-4.5]). Neither blood catheterisation (OR: 7.5; 95\% CI [0.95-59.3]) nor use of antibiotics (OR: $1.03 ; 95 \%$ CI [0.48 -2.2]) were significant risk factors.

Variables giving p-values less than 0.20 in univariate analysis were analysed using multiple logistic regression. In multivariate analysis, coming from care unit (adjusted OR 2.78; 95\% CI [1.256.25]), having diabetes (adjusted OR: 3.7; 95\% CI [1.3-11.2]) and past invasive procedure (adjusted OR: 
3.6; 95\% CI [1.1-11.9]) were independent risk factors

for acquired multiple resistance.

Table 1. Frequency of pathogenic bacterial isolates from different types at Antananarivo, Madagascar.

\begin{tabular}{|c|c|c|c|c|c|c|c|c|c|c|}
\hline \multirow[t]{2}{*}{ Organism } & \multicolumn{2}{|c|}{ Surgical wounds } & \multicolumn{2}{|c|}{ Deep pus* } & \multicolumn{2}{|c|}{ Blood } & \multicolumn{2}{|c|}{ Other** } & \multicolumn{2}{|c|}{ Overall } \\
\hline & $\mathrm{n}$ & $(\%)$ & $\mathrm{n}$ & $(\%)$ & $\mathrm{n}$ & $(\%)$ & $\mathrm{n}$ & $(\%)$ & $\mathrm{n}$ & $(\%)$ \\
\hline \multicolumn{11}{|l|}{ Gram-negative isolates } \\
\hline E. coli & 68 & $(27.4)$ & 12 & $(17.9)$ & 1 & $(5.6)$ & 7 & $(20.6)$ & 88 & (23.9) \\
\hline Proteus mirabilis & 11 & $(4.5)$ & 5 & (7.5) & 0 & --- & 3 & $(8.8)$ & 19 & $(5.2)$ \\
\hline Pr. Providencia - M. morganii & 22 & $(8.9)$ & 10 & $(14.9)$ & 0 & --- & 7 & $(20.6)$ & 39 & $(10.6)$ \\
\hline Enterobacter spp. & 31 & $(12.5)$ & 7 & $(10.4)$ & 0 & --- & 2 & $(5.9)$ & 40 & $(10.9)$ \\
\hline Other Enterobacteriaceae & 13 & $(5.2)$ & 1 & $(1.5)$ & 1 & $(5.5)$ & 1 & $(2.9)$ & 16 & (4.4) \\
\hline Other GNB & 8 & $(3.2)$ & 4 & $(6.0)$ & 3 & $(16.7)$ & 1 & $(2.9)$ & 16 & (4.4) \\
\hline Subtotal, Gram-negative isolates & 248 & $(46.5)$ & 67 & $(12.6)$ & 18 & $(3.4)$ & 34 & (6.4) & 367 & $(68.9)$ \\
\hline \multicolumn{11}{|l|}{ Gram-positive isolates } \\
\hline Staphylococcus aureus & 75 & $(66.4)$ & 18 & $(60.0)$ & 0 & --- & 10 & $(62.5)$ & 103 & $(62.0)$ \\
\hline St. Coagulase neg. & 0 & --- & 0 & --- & 5 & $(71.4)$ & 4 & $(25.0)$ & 9 & (5.4) \\
\hline Enterococci & 24 & $(21.2)$ & 3 & $(10.0)$ & 1 & $(14.3)$ & 2 & $(12.5)$ & 30 & $(18.1)$ \\
\hline
\end{tabular}


Table 2. Frequency of pathogenic bacterial isolates from different units at Antananarivo, Madagascar.

\begin{tabular}{|c|c|c|c|c|c|c|}
\hline & Trauma un & & Intensive units Care & & Visceral surgery un & \\
\hline & $\mathrm{n}$ & $(\%)$ & $\mathrm{n}$ & $(\%)$ & $\mathrm{n}$ & $(\%)$ \\
\hline E. coli & 37 & $(10.3)$ & 4 & (6.6) & 47 & 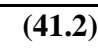 \\
\hline Klebsiella spp. & 25 & (7.0) & 11 & (18.0) & 11 & (9.7) \\
\hline Proteus mirabilis & 14 & (3.9) & 3 & (4.9) & 2 & (1.8) \\
\hline Pr.providencia $-M$. morganii & 34 & $(9.5)$ & 2 & (3.3) & 3 & (2.6) \\
\hline Enterobacter spp. & 30 & (8.4) & 3 & (4.9) & 7 & (6.1) \\
\hline Other Enterobacteriaceae & 12 & (3.4) & 3 & (4.9) & 1 & $(0.9)$ \\
\hline Pseudomonas spp. & 38 & (10.6) & 10 & (16.4) & 4 & (3.5) \\
\hline Acinetobacter & 33 & $(9.2)$ & 6 & (9.9) & 11 & (9.7) \\
\hline Other GNB & 10 & (2.8) & 5 & (8.2) & 1 & $(0.9)$ \\
\hline Staphylococcus aureus & 92 & (25.7) & 1 & (1.6) & 10 & (8.8) \\
\hline Coagulase neg. St. & 1 & $(0.3)$ & 7 & (11.5) & 1 & $(0.9)$ \\
\hline Enterococci & 17 & $(4.8)$ & 4 & (6.6) & 9 & (7.9) \\
\hline Streptococcus spp & 15 & $(4.2)$ & 2 & (3.3) & 7 & $6.1)$ \\
\hline Total & 358 & $(67.2)$ & 61 & (11.4) & 114 & (21.4) \\
\hline
\end{tabular}

Table 3. Percentage of gram-negative bacterial isolates resistant to antimicrobial agents (number of tested isolates in brackets).

\begin{tabular}{|c|c|c|c|c|c|c|c|}
\hline Gram-negative & $\begin{array}{c}\text { E. coli } \\
(\mathbf{8 8}) \\
\%\end{array}$ & $\begin{array}{c}\text { Klebsiella } \\
\text { spp. } \\
(47) \\
\%\end{array}$ & $\begin{array}{c}\text { Enterobacter spp. } \\
(\mathbf{4 0}) \\
\%\end{array}$ & $\begin{array}{c}\text { Proteus } \\
\text { Mirabilis } \\
\text { (19) } \\
\%\end{array}$ & $\begin{array}{c}\text { Other } \\
\text { Enterob* } \\
(\mathbf{5 5 )} \\
\%\end{array}$ & $\begin{array}{c}\text { Pseudomonas } \\
\text { spp. } \\
(\mathbf{5 2}) \\
\%\end{array}$ & $\begin{array}{c}\text { Acinetobacter } \\
\text { spp. } \\
\mathbf{( 5 0 )} \\
\%\end{array}$ \\
\hline Amoxicillin & 82.9 & 100.0 & 100.0 & 68.4 & 98.2 & --- & --- \\
\hline Ticarcillin & 82.9 & 100.0 & 47.5 & 47.4 & 43.6 & 32.7 & 72.0 \\
\hline Cefotaxime & 18.2 & 39.1 & 47.5 & 0.0 & 20.0 & --- & --- \\
\hline Ceftazidime & 18.2 & 39.1 & 47.5 & 0.0 & 20.0 & 1.9 & 62.0 \\
\hline Imipenem & 0.0 & 0.0 & 0.0 & --- & 0.0 & 1.9 & 44.0 \\
\hline Gentamicin & 28.4 & 42.3 & 45.0 & 0.0 & 25.5 & 7.7 & 76.0 \\
\hline Tobramycine & 39.8 & 48.9 & 47.5 & 11.1 & 30.9 & 15.3 & 46.0 \\
\hline Amikacin & 1.1 & 8.5 & 15.0 & 0.0 & 5.4 & 5.8 & 46.0 \\
\hline Nalidixic acid & 64.8 & 46.8 & 50.0 & 15.8 & 50.9 & --- & --- \\
\hline Ciprofloxacin & 52.3 & 40.4 & 32.5 & 5.3 & 40.0 & 3.9 & 72.0 \\
\hline Co-trimoxazole & 82.9 & 76.1 & 47.5 & 52.6 & 69.1 & 92.0 & 87.5 \\
\hline
\end{tabular}


Table 4. Percentage of Gram-positive bacterial isolates resistant to antimicrobial agents (number of tested isolates in brackets).

\begin{tabular}{|c|c|c|c|c|}
\hline \multirow[t]{2}{*}{ Drugs } & $\begin{array}{l}\text { S. aureus } \\
(103)\end{array}$ & $\begin{array}{c}\mathrm{CNS}^{*} \\
(9)\end{array}$ & $\begin{array}{c}\text { Enterococci } \\
(30)\end{array}$ & $\begin{array}{c}\text { Streptococci } \\
(24)\end{array}$ \\
\hline & $\%$ & $\%$ & $\%$ & $\%$ \\
\hline Penicillin & 92.2 & 77.8 & --- & \\
\hline Ampicillin & --- & --- & 16.7 & 4.2 \\
\hline Oxacillin & 13.6 & 22.2 & 93.3 & 8.7 \\
\hline Tetracyclin & 59.2 & 33.3 & 65.5 & 56.5 \\
\hline Erythromycin & 19.4 & 44.4 & 70.0 & 12.5 \\
\hline Lincomycin & 5.8 & 33.3 & 90.0 & 12.5 \\
\hline Pristinamycin & 1.0 & 11.1 & 73.3 & 8.3 \\
\hline Ciprofloxacin & 5.8 & 33.3 & 20.0 & 8.3 \\
\hline Gentamicin & 3.9 & 33.3 & 10.0 & 4.3 \\
\hline Vancomycin & 0.0 & 0.0 & 3.3 & 0.0 \\
\hline Teicoplanin & 0.0 & 0.0 & 3.3 & 0.0 \\
\hline
\end{tabular}

* CNS: coagulase negative Staphylococcus

As described in other studies, organisms associated with surgical site infections vary with the type of procedure and the anatomical location of the infections may become apparent only after patients are discharged, as observed previously in Thailand [10].

Risk factors for resistance to oxacillin in S. Aureus In univariate analysis (table 6), no risk factors were found for resistance to oxacillin except age.

\section{Discussion}

In countries where resources are limited, surgical site infections remain a major cause of nosocomial infections [9]. This study therefore mainly targeted surgery units. The study presents evident limitations but, since samples were collected by staff from the Pasteur Institute of Madagascar to ensure their rapid delivery to the laboratory, it was not possible to collect samples more than once a week from each unit.

Unfortunately, we were not able to determine the prevalence of nosocomial infections. Although we knew the number of patients present the days of the sampling, we did not know how many were hospitalized for more than 48 hours. However, the prevalence rate would have been very difficult to estimate since in Madagascar, as in many developing countries hospital stays are short and nosocomial operation, with a predominance of $S$. aureus observed in trauma units and of enterobacteria in visceral surgery. We observed a similar rate of $S$. aureus infections to that found (approximately 20.0\%) in a literature review [11]. Similarly to the results found in Cameroon [12], the percentage of E. coli infection in our study was greater than that in other developing countries [13-15].

This study provides insights into the problem of resistance in bacterial pathogens in Antananarivo, Madagascar. Our results demonstrated that, in general, isolates have high rates of resistance to antibiotics commonly used in developing countries. We also found a high rate of resistance to penicillins, first generation cephalosporins and cotrimoxazol. Therefore, cheap antibiotics such as amoxicillin, tetracyclin and cotrimoxazol are now of limited benefit in the treatment of infections in Madagascar. These results, probably due to overuse of broadspectrum antibiotics, confirm those of previous studies [6,7].

The high level of ciprofloxacin resistance among E. coli, and more generally Enterobacteriaceae, rules out the use of ciprofloxin as empirical treatment when invasive infections due to these pathogens are 
Table 5. Risk factors for nosocomial infection with Enterobacteriaceae resistant to third-generation cephalosporins in Antananarivo.

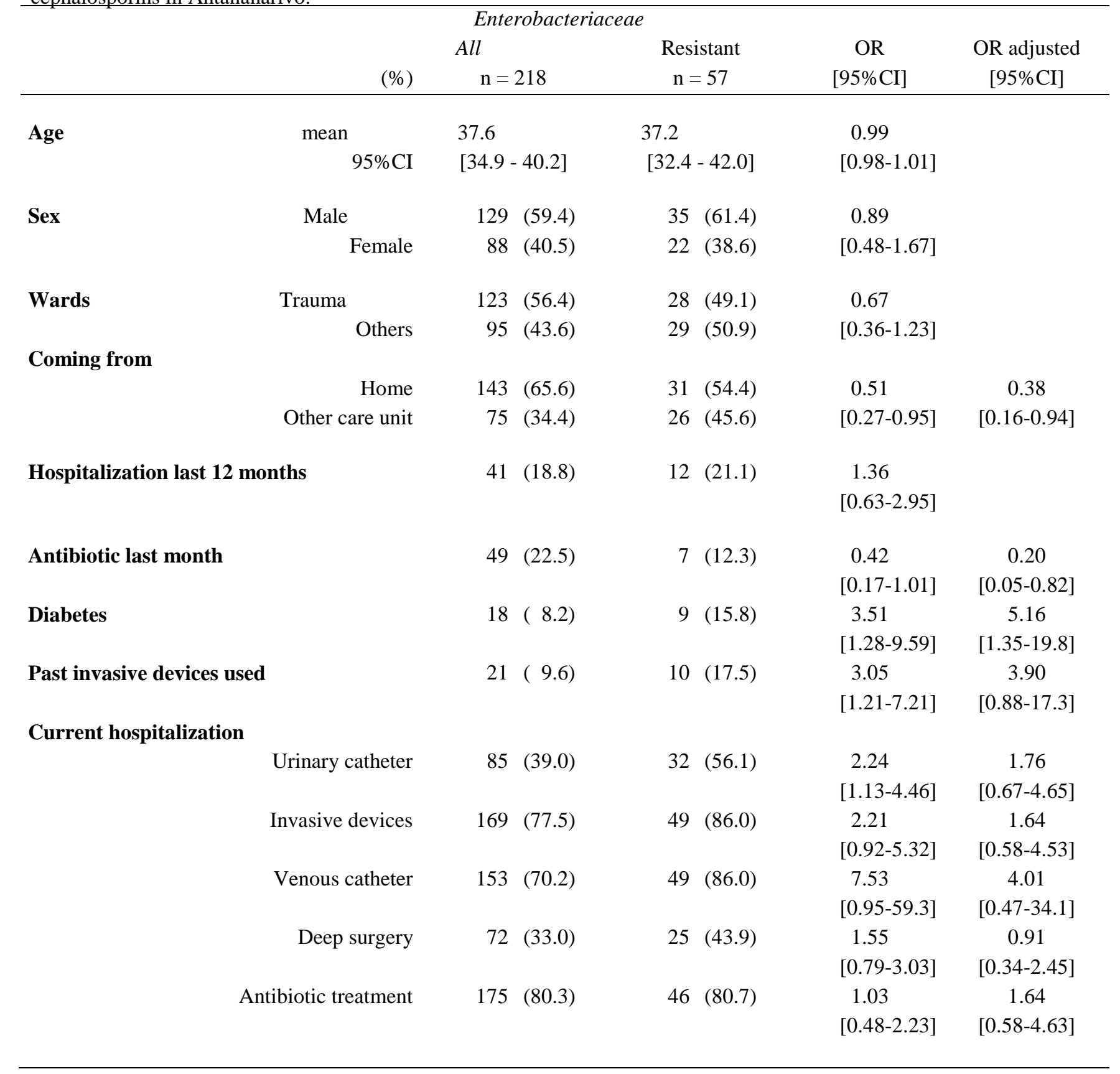

suspected. The rate of resistance to thirdgeneration cephalosporins is also worrisome because the alternative treatment (carbapenem) has limited availability in Antananarivo. This rate is similar to or even lower than that described in other developing countries [13-16] but higher than rates in developed countries [17-19].

The high prevalence of $A$. baumanii $(8.8 \%, \mathrm{n}=$ $47)$ and $P$. aeruginosa $(8.8 \%, \mathrm{n}=47)$ may have been exacerbated by failure of infection control in the hospitals. The overall rate of antibiotic resistance in
A. baumanii was higher than that in P. aeruginosa; this observation contrasts with previous results founds in South Africa [16]. Resistance to carbapenem (imipenem) in A. baumanii was $45.7 \%$, but $0.0 \%$ in $P$. aeruginosa. This high rate of resistance to carbapenem in A. baumanii in our study is striking given that this antibiotic is rarely prescribed in Madagascar. This result may be due to the clonal spread of a multi-resistant strain of $A$. baumanii. The prevalence of fluoroquinolon resistance was also lower in $P$. aeruginosa than $A$. 
baumanii (2.2\% vs. $76.1 \%)$. The high levels of antibiotic resistance throughout the study period in isolates of $A$. baumanii are of great concern because the limited choice of treatments threatens the successful management of these infections. None of the currently available single agents that we tested relatively low, this rate was higher than that observed in a previous study, in which the rate of oxacillin resistance among 68 strains isolated from nosocomial infections between 2001 and 2005 was $4.4 \%$ [6]. We did not observe resistance to vancomycin or teicoplanin. These antibiotics are not yet used in

Table 6. Risk factors for nosocomial infection with MRSA in Antananarivo.

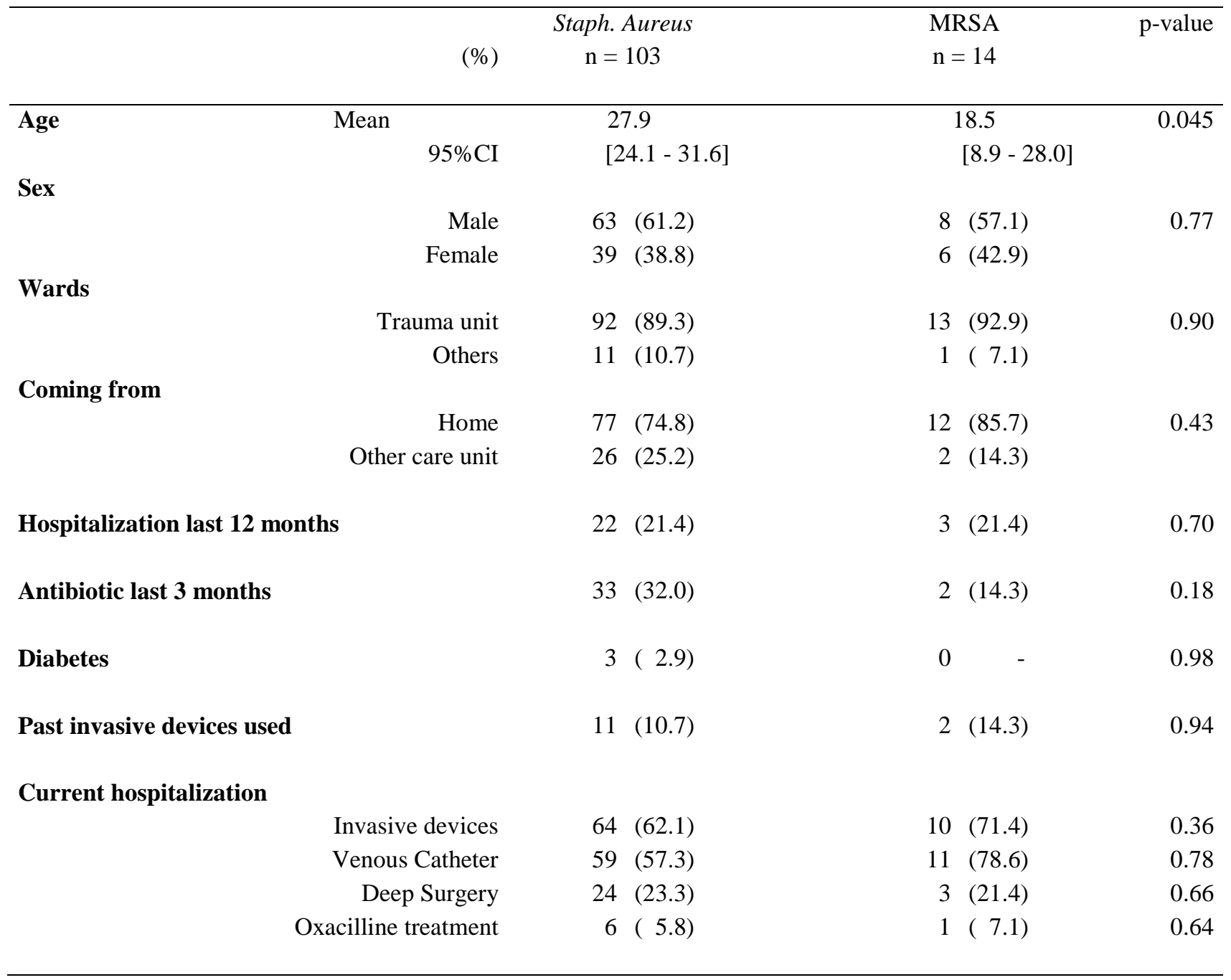

performed adequately to be considered as a suitable empirical monotherapy. Combination therapy should therefore be used until susceptibility results are available. In contrast, rates of resistance in $P$. aeruginosa in Antananarivo are much lower than those described in most countries [13-16,17,18].

The prevalence of MRSA varies greatly throughout the world, as a function of geographical region, site of infection and whether the infection is nosocomial or community-based. In this study, the rate of MRSA $(14.6 \%)$ was much lower than in most countries [13-16,17]. However, despite being
Madagascar because they are too expensive.

Patients admitted to hospitals in tropical regions of Africa are at increased risk of nosocomial infection. However, an accurate assessment of this risk is difficult due to a lack of published data. The main risk factors may be poor health care facilities, high microbial levels in the hospital and community environment, and uncertain health status among patients. The increasing number of reports of multiresistant bacteria is evidence of poor hospital sanitation. In this study, invasive procedures were identified as a major risk factor. Health care workers 
and patients must be educated about the importance of hand-washing, not performing unnecessary injections and transfusions and ensuring that these procedures are carried out in aseptic conditions, isolating patients with communicable diseases, handling waste products safely, and using antimicrobials properly.

We identified diabetes as a risk factor for infection by enterobacteria resistant to thirdgeneration cephalosporins. This observation could be explained by the fact that people with diabetes are more likely to be treated or hospitalised than other patients.

\section{Conclusion}

Our findings demonstrate the widespread problem of antibiotic resistance among nosocomial pathogens in two hospitals in Madagascar. Continued surveillance is necessary to guide appropriate empirical therapy for these infections. It is imperative that all professionals take an active role in infection control within their establishments. More resources should be provided to encourage good antibiotic practice and good hygiene in hospitals.

\section{Acknowledgements}

We would like to thank all the physicians and staff for their cooperation in this study, particularly Dr Samson Luc Hervé, Dr Rakoto-Ratsimba Herinirina, Dr Rakotosamimanana Johnny, Dr Tsiaviry Persisy, Dr Solofomalala Gaëtan Duval, Dr Rasolofondranoatra Helivao, Dr Ramarokoto, and Dr Godard Tovone.

\section{References}

1. Whitehouse JD, Friedman ND, Kirkland KB, Richardson WJ, Sexton DJ (2002) The impact of surgical sit-infections following orthopaedic surgery at a community hospital and a university hospital: adverse quality of life, excess length of stay and extra cost. Infect Control Hosp Epidemiol 23:183189.

2. Acar JF (1997) Consequences of bacterial resistance to antibiotics in medical practice. Clin Infect Dis 24: S17-S18.

3. Hsueh PR, Chen ML, Sun CC, Chen WH, Pan HJ, Yang LS et al. (2002) Antimicrobial drug resistance in pathogens causing nosocomial infections at a university hospital in Taiwan, 1981-1999. Emerg Infect. Dis 8: 63-68.

4. Tenover FC, Hughes JM (1996) The challenges of emerging infectious diseases. Development and spread of multiplyresistant bacterial pathogens. JAMA 275: 300-304.

5. Decousser JW, Pfister P, Xueref X, Rakoto-Alson O, Roux JF (1999) Acquired resistance to antibiotics in Madagascar: preliminary evaluation. Med. Trop. 59: 259-265.

6. Randrianirina F, Soares JL, Ratsima E, Carod JF, Combe P, Grosjean P, Richard V, Talarmin A (2007) In vitro activities of 18 antimicrobial agents against Staphylococcus aureus isolates from the Institut Pasteur of Madagascar. Annals of Clinical Microbiology and Antimicrobials 6: 5.
7. Randrianirina F, Soares JL, Carod JF, Ratsima E, Thonnier V, Combe P, Grosjean P, Talarmin A (2007) Antimicrobial resistance among uropathogens that cause communityacquired urinary tract infections in Antananarivo, Madagascar. J Antimicrob Chemother 59: 309-312.

8. Comité de l'Antibiogramme de la Société Française de Microbiologie. (2007) Recommandations 2007. Skov R, Smyth R, Larsen AR, Bolmstrom A, Karlsson A, Mills K, Frimodt-Moller N. SFM, Paris, France.

9. Probhakar P, Roje D, Castle D, Rat B, Fletcher P, Duquesnay D, Venugopal S, Carpenter R (1983) Nosocomial surgical infections: incidence and cost in a developing country. Am J Infect Control 11: 51-56.

10. Kasatpibal N, Jamulitrat S, Chongsuvivatwong V (2005) Standardized incidence rates of surgical site infection: a multicenter study in Thailand. Am J Inf Control 33, 587594.

11. Saadatian-Elahi M, Teyssou R, Vanhems P (2008) Staphylococcus aureus, the major pathogen in orthopaedic and cardiac surgical site infections: a literature review. Int $\mathbf{J}$ Surg 6: 238-45.

12. Pieboji JG, Koulla-Shiro S, Ngassam P, Adiogo D, Njine T, Ndumbe P (2004) Antimicrobial resistance of Gramnegative bacilli isolates from inpatients and outpatients at Yaounde central hospital, Cameroon. Int J Inf Dis 8: 147154.

13. El Kholy A, Baseem, H, Hall GS, Procop GW, Longworth DL (2003) Antimicrobial resistance in Cairo, Egypt 19992000: a survey of five hospitals. J Antimicrob Chemother 51: 625-30.

14. Bayram A and Balci I (2006) Patterns of antimicrobial resistance in a surgical intensive care unit of a university hospital in Turkey. BMC Infectious Diseases 6: 155.

15. Saïdani M, Boutiba I, Ghozzi R, Kammoun A, Ben Redjeb S (2006) Bacteriologic profile of bacteremia due to multi-drug resistant bacteria at Charles-Nicolle hospital of Tunis. Med Mal Inf 36: 163-66.

16. Brink A, Moolman J, Da Silva MC, Botha M (2007) Antimicrobial susceptibility profile of selected bacteraemic pathogens from private institutions in South Africa. South African Medical Journal 97: 273-279.

17. CDC NNIS (2004) National Nosocomial Infections Surveillance (NNIS) System Report, data summary from January 1992 through June 2004, issued October 2004. Am J Infect Control 32: 470-485.

18. InVS (2006) Enquête nationale de prévalence des infections nosocomiales, juin 2006. Rapport InVS 2007. Available: www.invs.sante.fr/publications/2007/ rea_raisin/rea_raisin_2006.pdf.. Accessed 11 January 2010.

19. Sligl W, Taylor G, Brindley PG (2006) Five years of nosocomial Gram-negative bacteremia in a general intensive care unit: epidemiology, antimicrobial susceptibility patterns and outcomes. Int J Inf Dis10: 320-25.

\section{Corresponding author}

Vincent RICHARD

Institut Pasteur of Madagascar - BP1274 - 101 Antananarivo Madagascar

Telephone number: 00261202241272

Fax: 00261202241534

Email: vrichard@pasteur.mg

Conflict of interest: No conflict of interest is declared. 